\title{
The ideal of Design College An Analysis and Its Historical Review of the Modern Design Education with Cultural Criticism
}

\author{
Hua Zhu ${ }^{1, a}$ and Tian Lan ${ }^{1, b}$ \\ ${ }^{1}$ Changchun University of Technology Changchun, Jilin, China 130000 \\ a645956568@qq.com, b16617636@qq.com
}

Keywords: Cultural criticism; Social value; "Cultural design"; "Scientific design"; Ideal product environment

\begin{abstract}
Cultural criticism makes the modern design concept produce, its social value defines the modern design education the idea and the practice. The beginning of Bauhaus cultural criticism had a strong color "ideal reality" color. It will be the ideal design institute implementation process to develop from the "cultural design" reactionary of traditional art into the current computer scienceled criticism of "scientific design" to the cultural industry. Scientific knowledge and methods define the connotation of "scientific design" education which is led by cultural criticism, which sublimates into the design education of interdisciplinary research. The decisive effect of cultural criticism on design education will also promote the emergence of "scientific cultural design".
\end{abstract}

\section{Introduction}

Modern design has less than 200 years of history which is in the unprecedented transformation of human society, of which modern design education of 100 years of history is more of the significance of culture and science from knowledge to practice. From Bauhaus till now, how to define the connotation of modern design education for many design colleges? We introduce the concept of "cultural criticism" and focus on some kind of critical spirit that design education organization gives design education. The construction and development of this spirit is the historical logic of modern design education. From the modern design "culture - science" transformation, explore design education and practice in the history process to achieve the ideal design education to inspire our reflect on design education and let us learn from nutrition.

\section{Modern Design of Cultural Criticism}

The important component of modern design is still "cultural design". It is the results of the use of science and technology on the traditional cultural criticism. From the perspective of macro-decisive constraints, the division of the traditional design and the modern design is the reflection of the process of the unity of culture and science.

The development of modern design is the process of reactionary art as a "cultural design". Since ancient times, the philosophy of design and aesthetic tradition have been ingrained. In the middle of the 19th century, because of the rapid development of capitalist industry, the design played the same dual role as the capitalist industry workers: both the carrier of capitalist culture and the creation of its cultural value. Then, the understanding of the design cannot follow the traditional aesthetic form of art, there must be a new standard. So the modern design can be produced with the historical mission that must be anti-traditional cultural criticism. As fundamental means of cultural criticism, science and technology have played a resolute and seductive role in creating the new world of mankind from the industrial society so far, and decided the result that design own pioneer development to computer science leading for nearly 20 years. We temporarily call it "scientific design".

After the Second World War, there was a problem in the process of social development - the cultural industry, "scientific design" is not only a criticism of the cultural industry. Since World 
War II, modern design and manufacture produced more commercial, formal, visual design products, which formed the situation the general lack of social value of design, while creating a commercial culture and consumer culture. In the 1990s, "scientific design" rose, computer science played a role of cultural criticism whose significance lied in inheriting the tradition of cultural criticism since the modern design, criticizing the cultural industry and trying to establish a new world which is gradually out of human desire. At this point, the modern design history process achieved two cultural criticism: the criticism of the aesthetic tradition and the criticism of the cultural industry. In the middle, modern design education is deeply influenced and fueled.

\section{Social Value - Concept and Practice of Modern Design Education with Cultural Criticism}

The critical design of modern design is also deeply embedded in modern design education. Since Bauhaus, modern design education has gradually formed two cores: cultural awareness and scientific knowledge, methods. The cultural criticism of design education lies in the social value achieved through the teaching activities collectively by the design educators.

Design education is to make students have advanced design concepts to adapt to and even promote the development of the society, cultural criticism is an important means of forming a design concept. The history of modern design education proves that its essence is the cultivation of design concept, cultural criticism makes the design concept be advanced and decides the historical value of design education. The cultivation of design concepts is the process of spiritual construction, which requires teachers to collect the following characteristics: Clarify the social standpoint of design education; the concept of education should be consistent with the general law constructed by the spirit of the times; use critical teaching ideas to guide students design practice; reveal the inherent contradictions in the process of social history, which decides the grasping and applying of design knowledge - the social contribution of design.

In the process of the development of modern design education, as an important means of education, design practice plays a cultural critical role. Design practice has a double from property, one is the social practice attributes of design which is as a social activity; one is the educational attributes of design which is to train the design concept of students in the process of education. The same goal is to solve the social problems, promote social development. The two have a common social significance which is to have cultural critical design practice. To achieve the critical design practice of social value of design must be higher than that of the design practice which is the design industry develop with general requirements, which means education is higher than the market. As the collective of design educators and educational concepts, the role of Design College is to train students to guide and improve the continue promotion of critical design practice ability of social development through the design concept with the meaning of cultural criticism. Deeply study the motivation, position and its development and social contribution of the critical design practice of Design College which met the social progress to summarize as part of the historical law of modern design education. The realization of historical social values of modern design education is needed the remodel of the collective idealist spirit of design educators.

\section{"Ideal Reality"- The Beginning of the Cultural Criticism of Modern Design Education}

From the general methodology of defining things, the commonality between "design" and "education" lies in the idealized goal and the gradual, quantitative and efficient process of realizing it. Which can be summarized as that the former is "ideal", then the latter can be regarded as "reality." According to the social values of cultural criticism, the idea of modern design education can be called "ideal reality."

The origin of cultural criticism of modern design education can be traced back to social moral criticism of John Ruskin (1819 1900). He inspected the "art and technology separation" of the products exhibited by the World Expo in 1851, and his thought was far from the early years of industrial design. In the book The Stone of Venice (1853), he carried out ideological roots that he tried to combine the moral and social health of a country with its buildings and the quality of the 
design, and he believed that a healthy society embodied in the skills and creativity of its workers. He did not believe in capitalism and his moralist position thought that capitalism brought disaster to the society and life. It can be said that John Laskin's thought was beyond the product aesthetics at early time, and improved the review to the design o the height of social criticism. When Laskin died in 1900, the dissatisfaction with the social status quo after the industrial revolution has developed into a broad cultural criticism basis of modern design education of cultural criticism thought tread. Herman Muthesius (1861-1927) pointed out that the design should be "the visual manifestation of the internal power of the times" to make "the form enter the general culture with the goal of reflecting the unity of the country." His view of "design education saves Germany" (2) is undoubtedly the earliest expression of the design educational ideas with cultural criticism, prompting Gropius to create Bauhaus Design Institute to carry out modern design education. Thus, the modern design culture of critical thinking has become the fundamental concept of modern design education, as the cornerstone of modern design institute, Bauhaus Design Institute was established. Gropius's Bauhaus Declaration (1919) described: "Let us look forward to, conceive and create the future of the new building, use it to combine everything - architecture and sculpture and painting - in a single form. In the form of one day, he will ascend to heaven from the hands of the millions of workers and symbolize the new faith of the future as clear as crystal." (3) It is clear that the social value foundation and the cultural critical thought of the educational philosophy of these design educators are inherited in the development of design education after World War II.

In 1955, West Germany formally established Ulm Design Institute which is known as "new Bauhaus". The cultural criticism idea with social significance of it is more comprehensive reflected: to basically reflect the social significance of aesthetic and design in the modern industrial society; to widely explore the relationship between aesthetics and politics, functionalism and liberalism; to develop system design method through contact with enterprises; to introduce semiotics and sociology, etc., which retains the last rare cultural ideal for the development of the design in future commercialization community. At this point, the cultural criticism of the social values of design education and the realization of the ideal goals which is achieved based on this is an important part of modern design education.

\section{Scientific Knowledge and Method: Cultural Criticism Leads the Education of "Scientific Design"}

The modern design education, which began in Bauhaus, has three historical missions: to build a new order to achieve the construction of a new cultural order, the ultimate goal is to establish a new social order. The ideological tool to complete missions is cultural criticism. The design education with cultural criticism ensure the talent supply to reconstruct the design and culture and establish a new cultural order. The talent training of "scientific design" shall be achieved by cultural criticism.

In order to achieve the goal of "concerning about the mission and destiny of the German nation", Bauhaus's design education combines natural science and engineering technology. The design education adopts scientific approach to teach scientific knowledge. Design education is rooted in large-scale industrial production of designed products. Bauhaus science and rational design education view are to solve the two core issues concerned by Herman Muthesius: First, the advantages of German industry in Europe, second is the cultural renaissance of the German nation. At that time, the widespread dissemination of public opinion in Germany was "to use a collectivist ideology to overcome the chaos of traditional cultural disintegration and social transformation, to improve the efficiency of large - scale industrial production and to reduce the administrative difficulties encountered by the state", which reflected the ideals of building a new social and cultural order of Bauhaus Design Education, which was largely inherited in Ulm Design Institute after the war. In 1937 and 1938, Gropius and Mies came to the United States, because of the lack of social values. The United States international design including their works lost the social ideals of the modern design naturally. 
So, in 1951, "Texas Mounted Police" of the University of Texas Austin School of Architecture re-designed the new order. Teaching focus changed from the internal logic controlled design structure operation, so that students effectively find their own design strategies. "Texas Mounted Police" design education was the call for the education reform of the scientific design method, which made design education completely be out of the style. The mystery of design was no longer limited to the monopoly of the spirit creations of masters, but could be widely studied and used. The design education taking the classic design as the objects of cultural criticism scientifically and systematically cultivated a large number of social design talents who met the social needs of the rapid development of science and technology after World War II.

In 1959, served as the assistant coach of Bucischier, the main force of "Battle of Texas," Bernard Heisley came back to Swiss Zurich Institute of Engineering (ETH) to teach and his "highly structured curriculum" scientific teaching methods became the dominant concept of ETH design education to construct design new order. Around the core, a group of teachers built the ideal order of design education adopting scientific teaching methods to make design become the process which is rational and can be discussed and judged. In the 1960s, ETH, in addition to daily teaching, ETH also offered professors and students to participate in Design Seminar, such as Seminar woche and Information skolloquien. In the 1990s, computer science and network technology became representatives of the new social and cultural, which constitutes the mainstream to go deeply in ETH design education. The Institute's Digital Manufacturing National Center (NCCR) includes digital construction laboratories and arbitrary shaped materials laboratories, which are to explore the durability of the design concept and construction of specific materials, in order to realize the seamless docking of design and manufacture. The design education of ETH is the process constructed by the construction and the development of the design education of a new order to explore the new order of the future human settlements.

Another two examples that used "scientific design" education based on computer science to achieve a new cultural order are AA School of British Architecture Union School of Architecture and MIT AD+P of Massachusetts Institute of Technology School of Architecture and Urban Planning. In 1997, AA set up Design Research Laboratory (DRL) with the design concept is to set up the aesthetic system of science and art, which is to demonstrate its desire for a new order of design and culture. Establish design history and theoretical teaching system taking Parametric as a clue, and design teaching practice taking scripting as the core technology. Almost the same time, the design education concepts and practices of $\mathrm{AD}+\mathrm{P}$ of the United States MIT Institute of Architecture and Urban Planning also focused on computer science. On the one hand, it is the criticism to society virtual, non-materialized, fragmented and other negative effects of the design of the network information; on the other hand, create new practical design education methods to break the situation where design theory determines US design education for long-term. The combination of the two is the concept of design education which is to emphasize the material of practical logic of design and the discussion of living environment relationship.

As early as the 1960s, Herbert Simon put forward the concept of "design science" in response to computer science, organizational openness, artificial intelligence and other new social development. But as Simon elaborated: "Design science is artificial science", which is different from the natural sciences, it is also a "cultural design", the relative new design order is the computer science-led "science design" from 1990s. Throughout the history of modern design education, that is, the education infiltration history that scientific knowledge and methods developed to "cultural design". But now the "scientific design" will gradually import human society history and become the component of "more meta-culture design" in the future. Therefore, Patrick Schumacher classified the influence of all the design led by computer science as a "parametric" with the aim of creating a design discipline which can capture, control and even shape to adopt to the today and the future when the distributed electronic network continuously develop, in order to adapt to the cultural development which is needed more comprehensive scientific elements of the new order of the world. 


\section{Ideal Product Environment Construction —-Multidisciplinary Crossed Modern Design Education}

The development of post-industrial and post-modern culture expands the boundaries of design, and the responsibilities of design of "cultural-social" is based on the viewing and creating of the overall living environment. The construction of the ideal product environment and the discovery of new users are the new goals of design. This tendency has made a significant change in the mission of modern design education: to build "design - culture - society" new order. The design education with the characteristics of cross - disciplinary gradually formed.

In the 1960s and 1970s, the Art Design Methodology of British Royal Academy provided the necessary preparation for enterprise product $\mathrm{R} \& \mathrm{D}$ which achieved design participation process and efficiency management and also made the design gradually be evolved from scholar experience to a real discipline which had academic rigor and paid attention to practical experience to knowledge and wisdom. (10) Carnegie Mellon University of 1980s was the interdisciplinary design education representing design, mechanical and business, which became the leader advocated and promoted by Professor Herbert Simon and Donald Norman with computer science and psychology expertise.

In the 1990s, AA, ETH, MIT and other famous design schools passed multidisciplinary interdisciplinary teaching of architectural design, structural design, robotics, materials science and computer science and tried to expand the scientific road of design. Entering the $21^{\text {st }}$ century, d. School of Stanford University cooperated with commercial design company and fully transformed into the design education of the brand business model operation. The brand effect was understood by the public. Design education developed into a more "scientific culture design" education.

To sum up, to analyze the modern design education from the perspective of cultural criticism, we can clearly see that the evolution of design education thought is at the core of revealing the inherent law of social change. Looking back at the history of modern design education, it has always been the responds on the design education of social spirit, science and technology, moral criticism in different stages which the break and change of the modern design thought follow, which shows that culture criticism is the foundation of modern design education and the social contribution of modern design education.

\section{References}

[1]Xin Xiangyang, Context, Content and Experience in Design Education Reform[J], Declaration, 2016(7).

[2]Tang Keyang, The Stories of Design College[M]. Beijing: Peking University Press. 2011-08.

[3]Li Yanzu. Selected Works of Foreign Design Art[M]. Beijing: Tsinghua University Press. 200608 .

[4]Zhang Yonghe, Tian Ruifeng. Interview of Zhang Yonghe[J]. World Architecture. 2009(1).

[5] Xu Weiguo. Parametric Architectural Design[J], Journal of Architecture. 2006(12).

[6] [US] Victor Margolin Edited. Sha Liu and Zhang Duoduo translated. [M]. Beijing: Construction Industry Press. 2010-09.

[7]Yang Haifeng. Cultural Concept in the View of Cultural Philosophy - Also on Western Marxist Theory of Cultural Criticism[J]. Journal of Nanjing University: Philosophy, humanities.2017(1). 